\title{
Mitochondria COI-Based Molecular Characterization and Genetic Analysis of the Fenazaquin Selected Resistant Strain of Two-Spotted Spider Mite, Tetranychus urticae Koch
}

\author{
Rakesh Kumar Sharma ${ }^{1}$, Manmeet Brar Bhullar ${ }^{2}$ and Satnam Singh ${ }^{3}$ \\ ${ }^{1}$ Dr D R Bhumbla RRS, Ballowal Saunkhri, Punjab, India \\ ${ }^{2}$ Department of Entomology, Punjab Agricultural University, \\ Ludhiana-141004, Punjab, India \\ ${ }^{3}$ RRS PAU, Faridkot, India \\ *Corresponding author
}

\begin{abstract}
A B S T R A C T
\end{abstract}

\begin{tabular}{|c|}
\hline Keywords \\
\hline $\begin{array}{l}\text { Tetranychus } \\
\text { urticae, METI } \\
\text { acaricides, } \\
\text { Resistant, mt COI }\end{array}$ \\
\hline Article Info \\
\hline $\begin{array}{l}\text { Accepted: } \\
\text { 18 January } 2019 \\
\text { Available Online: } \\
\text { 10 February } 2019\end{array}$ \\
\hline
\end{tabular}

\section{Introduction}

The two-spotted spider mite, Tetranychus urticae Koch (Acari: Tetranychidae) is an important agricultural pest with a global distribution and is one of the economically most important pests in a wide range of outdoor and protected crops worldwide (Belay et al., 2018). This mite has a great
The two-spotted spider mite, Tetranychus urticae Koch (Acari: Tetranychidae) has emerged as an important agricultural pest in a wide range of outdoor and protected crops worldwide. Fenazaquin is METI-acaricide which is used extensively and frequently for the management of this mite has resulted in the development of resistance. So, present studies were conducted to investigate molecular characterization and genetic analysis based on mtCOI sequence between fenazaquin resistant and susceptible population of $T$. urticae as very limited information is available regarding mutation/variability in genes involved in imparting resistance. Fenzaquin resistance population was developed in the laboratory by giving selection pressure with fenazaquin for 15 generations leading to 166.49 fold resistance when compared with susceptible population. Molecular characterization of resistant and susceptible population revealed no changes in genes structure of $m t C O I$ in the resistant compared to the susceptible population. In our studies high level of resistance to fenazaquin didn't show any change in the amino acid sequence of COI region of resistant and susceptible populations Thus results revealed mtCOI as a stable gene which is least influenced by acaricide resistance. 
high prolific rate, short life-cycle, high reproductive potential, arrhenotokous reproduction, polyphagous feeding habit, coupled with their extremely dispersal behavior (Stumpf et al., 2001; Croft et al., 1988; Knowles et al., 1997 and Ramasubramanian et al., 2005).

Mitochondrial electron transport inhibitors (METI's) belong to a class of acaricides, which are known to effectively control $T$. urticae and other tetranychid mite species for many years, including populations resistant to other chemical classes of insecticides/acaricides. There are many reports of acaricides becoming ineffective against $T$. urticae after short period of their use. TSSM or $T$. urticae has developed resistance to many categories of acaricides like organotins compounds, carbamates, bifenthrin, organophosphates, dicofol, abamectin, METI compounds (like fenazaquin, fenpyroximate, pyridaben etc.) hexythiaziox, clofentezine and chlorfenapyr. As a consequence, $T$. urticae has attained the dubious reputation to be "the most resistant species" in terms of the total number of pesticides to which it has become resistant (Van Leeuwan et al., 2010)

Fenazaquin attack a target-site in complex I (NADH: ubiquinone oxidoreductase) of the mitochondrial respiratory pathway (Hollingworth et al., 1995). Resistance to METIs has been reported in a number of regions and crops (Sharma and Bhullar, 2018). The resistance of two-spotted spider mite to METI-acaricides has already been reported from many countries all over the world, including Korea, England, Australia and Belgium (Van Pottelberge et al., 2009, Cho et al., 1995 and Herron et al., 1998)

Molecular approaches based on marker DNA sequence comparison have been introduced as tools for the identification of these species
(Vogler and Monaghan, 2007). Two molecular markers, mitochondrial cytochrome oxidase subunit I (mtCOI) and ribosomal RNA internal transcribed spacer 2 (ITS2), have been used extensively in the classification of Tetranychidae mites (Navajas et al., 1992). The mitochondrial gene coding for the subunit I of the cytochrome oxidase (mt COI) are commonly employed as molecular markers and they have already proved to be useful for separating distant groups of individuals within an insect species and resolving population genetic structures (Behura, 2006).

Navajas et al (1998) reported that 5' end of the mitochondrial COI gene is extensively used as a barcode to identify Tetranychus species and to analyze their phylogenetic evolution. The control of T. urticae in Punjab has been and still is largely based on the use of acaricides. Fenazaquin is widely used for control of $T$. urticae and other pests such as $P$. ulmi on apple and citrus. The extensive and frequent use of this acaricide facilitates resistance development in some populations of T. urticae in Punjab (Anonymous, 2018). Molecular basis helps in better understanding the development of resistance including strategies to avoid resistance and to manage spider mites when resistance is present. The objectives of this research were molecular analysis of resistant and susceptible population of $T$. urticae for genetic differences based on mtCOI.

\section{Materials and Methods}

\section{Rearing of susceptible $T$. urticae population}

The susceptible population of $T$. urticae was maintained on brinjal without exposure to any acaricide in the screen house and isolated from possible contaminants (i.e. pesticides and other arthropods for generations. Fenazaquin (Magister) was used for resistance 
studies that act as Mitochondrial complex I electron transport inhibitor.

\section{Development of fenazaquin resistant population}

The adult populations of $T$. urticae population that was collected from Patiala exhibited maximum resistance (24.65) against fenazaquin. Further resistance population was developed as per protocol by Sharma et al., (2018). The acaricide resistant and susceptible populations of $T$. urticae were used to assess the genetic diversity in mtCOI.

Molecular characterization and genetic analysis of resistant and susceptible $T$. urticae populations

DNA was isolated using NucleoSpin ${ }^{\circledR}$ Tissue XS (Macherey-Nagel-MN) kitas per manufacturer's protocol, which Isolated was analyzed by agarose gel electrophoresis for quality and by UV spectrophotometry for concentrations. The resistant and susceptible populations were investigated for molecular differences using mitochondrial cytochrome oxidase I (mtCOI) gene region, which has been universally accepted as taxonomically important' DNA barcode' region. Set of primers specific to $\mathrm{mtCOI}$ region of $T$. urticae were designed from the genome database specific to mitochondrion (http:// bioinformatics.psb.ugent.be/orcae/overview/ Tetur) of this organism and custom synthesized through Integrated DNA Technologies, Inc, Coralville, IA, USA..

PAU_Acro 8204: TATCAACAAATCAT AAAAATATTGG; PAU_Acro 8912: TATACTTCTGG ATGA CCAAAAAATCA

\section{PCR amplification of mtCOI DNA}

PCR amplification of mtCOI from $T$. urticaetotal DNA was carried out in a reaction volume of $20 \mu \mathrm{L}$, which contained:

\begin{tabular}{|c|c|c|}
\hline Component & $\begin{array}{l}\text { Stock } \\
\text { concentration }\end{array}$ & Volume $(\mu \mathrm{L})$ \\
\hline Insect DNA & $\sim 20.0 \mathrm{ng} / \mu \mathrm{l}$ & 2.0 \\
\hline F primer & $10.0 \mu \mathrm{M}$ & 1.0 \\
\hline $\mathbf{R}$ primer & $10.0 \mu \mathrm{M}$ & 1.0 \\
\hline dNTPs mix & $1.0 \mathrm{mM}$ & 5.0 \\
\hline Taq polymerase & 5.0 units $/ \mu \mathrm{L}$ & 0.6 \\
\hline Taq buffer (with $1.5 \mathrm{mM} \mathrm{MgCl}_{2}$ ) & $10 \mathrm{X}$ & 2.0 \\
\hline Sterile Milli-Q $\mathrm{H}_{2} \mathrm{O}$ to make $20 \mu \mathrm{l}$ & - & 8.4 \\
\hline
\end{tabular}

PCR amplified products were resolved by horizontal agarose gel electrophoresis using 1.0 per cent $(\mathrm{w} / \mathrm{v})$ agarose gel (supplemented with ethidium bromide @ $1.0 \mathrm{mg} / \mathrm{l})$ in $1 \mathrm{X}$ TAE buffer. The agarose blocks containing the specific amplified DNA band were cut from the agarose gel with a clean, sharp scalpel blade and transferred to a $1.5 \mu \mathrm{L}$ microcentrifuge tube and purified using 'QIAquick Gel Extraction Kit' (Qiagen) as per manufacturer's protocol. The purified DNA fragments were cloned into a 'PCR cloning vector' pGEM $^{\circledR}$-T Easy Vector Systems (Promega) and transformed into Escherichia coli JM109 host cells for mass multiplication of plasmid. One hour grown culture was spread $(80-100 \mu \mathrm{l})$ for selective growth of transformants on LB-Amp-X-GALIPTG agar (LB agar supplemented with ampicillin@100 $\mu \mathrm{g} . \mathrm{mL}^{-1}$ in Petri plates. The Petri plates were incubated overnight at $37^{\circ} \mathrm{C}$ for selection of the white recombinant clones from individual bacterial isolates. 
Three individual recombinant (white) clones from individual plates were picked up with a sterile tooth pick, inoculated into culture tubes containing $3 \mathrm{~mL}$ of LB-Ampicillin broth and the tubes were incubated overnight at $37^{\circ} \mathrm{C}$ under shaking conditions (180 rpm). Using this broth culture, miniprep plasmids were isolated using 'alkaline lysis method'. The size of insert DNA, in different recombinant plasmids was determined by PCR amplification using insert specific primer sets (CO I) and universal $\mathrm{M}_{13}$ primers. The recombinant plasmid was also double restricted with restriction enzymes EcoR1 and Pst1 (Fermentas Life Sciences) for further confirmation of the insert. The sequencing grade plasmid DNA was purified from the respective recombinant clone using 'Gene Elute ${ }^{\mathrm{TM}}$ Miniprep Plasmid Kit' of 'Sigma' as per manufacturer's protocol. The clones were sequencedthrough Custom Sequencing Services of ' $\mathrm{M} / \mathrm{S}$ Eurofin Genomics, Bangalore, India. The obtained sequences were analysed using Megalin, SeqMan, editSeq and Seqbuilder suits of lasergeneDNA star for nucleotide alignment amongst individuals of resistant and susceptible population. Any change in nucleotide sequence in resistant population was recorded.A

\section{Results and Discussion}

\section{Development of fenazaquin resistant population of $T$. urticae}

T. urticae population that was collected from Patiala (exhibited maximum resistance of 24.65 fold against fenazaquin) was exposed to serial concentrations, mortality was recorded after $24 \mathrm{hrs}$ and $\mathrm{LC}_{50}$ was determined and selection pressure were applied unless there was no further change in $\mathrm{LC}_{50}$ value. Finally, the $\mathrm{LC}_{50}$ values were calculated for the $\mathrm{F}_{15}$ generation as there was not much change in $\mathrm{LC}_{50}$ value and this population with 166.49 fold resistant was designated as fenazaquin selected resistant population. The acaricide resistant and susceptible populations of $T$. urticae were used to assess molecular mechanism of resistance.

\section{Molecular Characterization of resistant and susceptible populations of T.urticae}

The T. urticae populations from PatialaPunjab have been compared with laboratory maintained susceptible population from based on mtCOI region.

Extraction and quantification of total DNA from $T$. urticae adults from resistant and susceptible population

The DNA was isolated from both resistant and susceptible populations of $T$. urticae and was run on 1.0 per cent agarose gel in TBE buffer. A single condensed high molecular weight band free from degradation was obtained in from whole body tissues of both susceptible and resistant populations (Fig. 1). The DNA concentration as determined by spectrophotometer ranged between $0.76 \mu \mathrm{g} / \mu 1$ and $1.23 \mu \mathrm{g} / \mu \mathrm{l}$. The quality of DNA was determined by $\mathrm{A}_{260} / \mathrm{A}_{280}$ ratio which ranged between 1.78 and 1.92 for two sample tissues each of resistant and susceptible populations. The gel electrophoresis, quantity and quality revealed the good quality of DNA obtained for subsequent molecular analysis of $T$. urticae adult samples from resistant and susceptible population.

\section{Molecular characterization of resistant and susceptible $T$. urticae populations- mtCOI region}

Mitocondrial COI region has gained global importance and is being universally accepted as taxonomically conserved region for insect species and biotype/ strain identification. Studies have suggested that high level of acaricides/insecticide resistance may bring about slight changes in nucleotide sequences 
of this mitochondrial DNA region (Maitra et al., 2000, Catania et al., 2004 and Feyereisen, 2005). The specific primers were used to amplify 709bp DNA fragments of COI gene from the mitochondrial DNA of both susceptible and resistant population. Size of these fragments was similar to the expected size available in the NCBI database (NCBI, 1988) (www.ncbi.nlm.nih.gov). The single clean amplified band supported the specificity of desired region from both resistant and susceptible populations (Fig. 2).

\section{Custom sequencing of cloned COI DNA fragments}

The sequencing grade recombinant plasmid (Fig. 3) from three different clones of COI fragments from resistant and susceptible variants were purified and sequenced bidirectional through Eurofin Genomics Ltd, Bangalore using $M_{13}$ reverse and forward primer. The raw sequence data was processed using seqMan module of Lasergene DNA star software for removing the vector sequences and making a single sequence contig from the respective sequences of resistant or susceptible populations. The individual clones as well as both the complimentary DNA strands were proof read for any misread bases by comparison with chromatograms of original sequence (Fig. 4). The whole sequence of each individual strand was completed by aligning the sequence of one strand with that of the reverse complimentary sequence to yield a single sequence contig.

The final contigs from the respective population were aligned to form a single sequence in seqMan which was translated using seqBuilder module of Lasergene- DNA star. The mtCOI region sequence from susceptible and resistant populations was submitted to "GenBank Database" using
Banklt. The GenBank accession number assigned to COI sequence from both the submitted sequences are MF152824 and MF152825.

\section{Multiple alignment of COI nucleotide sequence and derived amino acid sequence}

Multiple alignment of COI nucleotide sequence for both the resistant and susceptible population of $T$. urticae established existence of codon substitution at nucleotide position at $177,444,580$ and 687 represented by substitution with G,T, A and T, respectively in resistant population compared to susceptible population (Fig. 5).

The codon substitution however didn't result in any change in the predicted amino acid sequence of both resistant and susceptible population consequently no change in the protein has been observed (Fig. 6). The mtCOI region of mitochondrial DNA is highly conserved and has been globally accepted as the gene of taxonomic importance. This fragment has been widely used for the identification of $T$. urticae species as well. The usefulness of the COI region for delineating tetranychid species has been investigated in several studies (Hinomoto et al., 2001, Hinomoto and Takafuji., 2001, Navajas et al., 1994, 1996a, 1996b, 1998, Toda et al., 2000 and Xie et al., 2006a). Recently, a DNA barcoding approach was used to identify tetranychid species (Hinomoto et al., 2007). Partial COI sequence of 1257 nucleotides amplified and sequenced in ten T. urticae strains identified all strains as $T$. urticae when compared with available COI sequences in public databases (NCBI). The 709 bp sequences of mtCOI region of susceptible and resistant population showed no significant differences in nucleotides. 
Fig.1 Total DNA isolated from fifty $T$. urticae female adults. $2 \mu 1$ of each DNA sample was loaded in $1 \%$ Agarose ETBR Gel (Susceptible-S1, S2, S3 and resistant- R1, R2, R3 population)

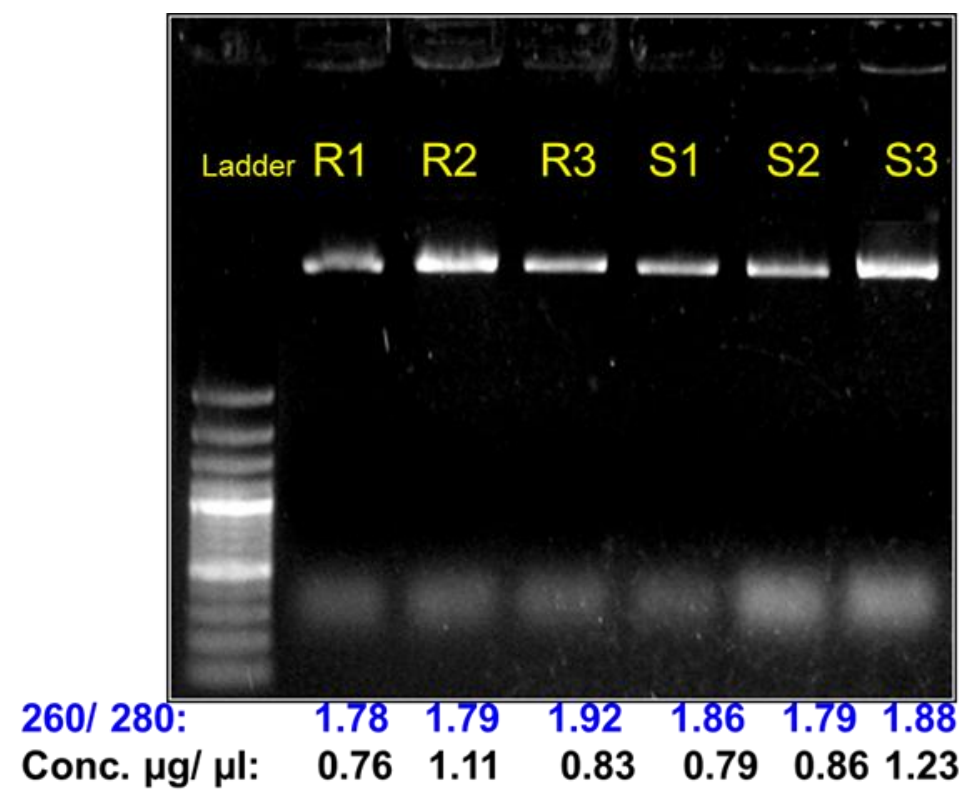

Fig.2 e PCR amplification of mt COI region (709bp) with mt COI specific primer set Custom sequencing of cloned mtCOI DNA fragments

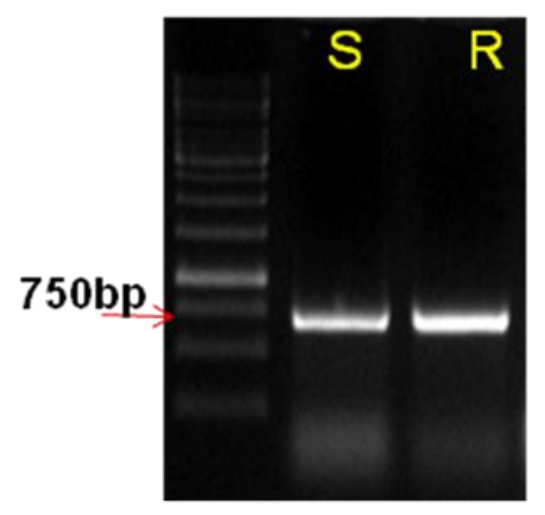

Fig.3 Sequencing grade plasmid on $1 \%$ agrose gel for quality check prior to sequencing

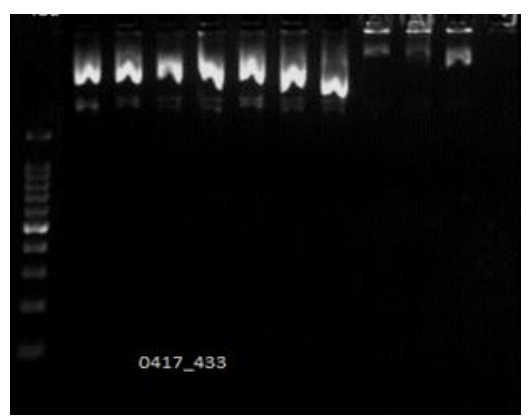


Fig.4 Comparative analysis of the two similar sequences from different clones using chromatogram

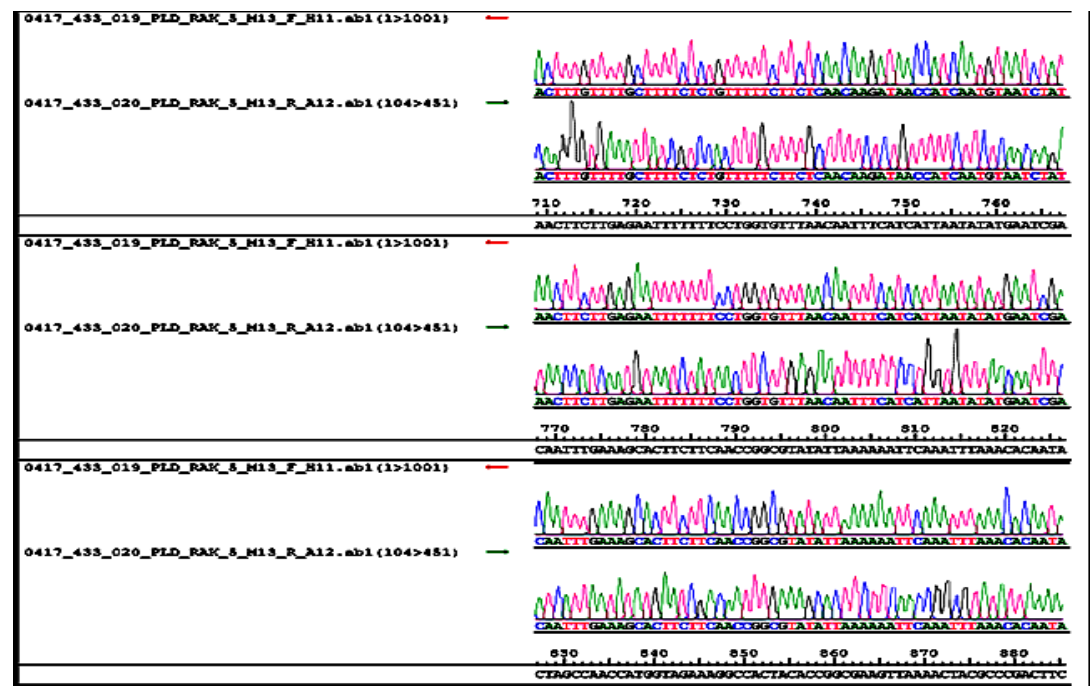

Fig.5 Multiple alignment of COI nucleotide sequence of resistant and susceptible populations of $T$. urticae

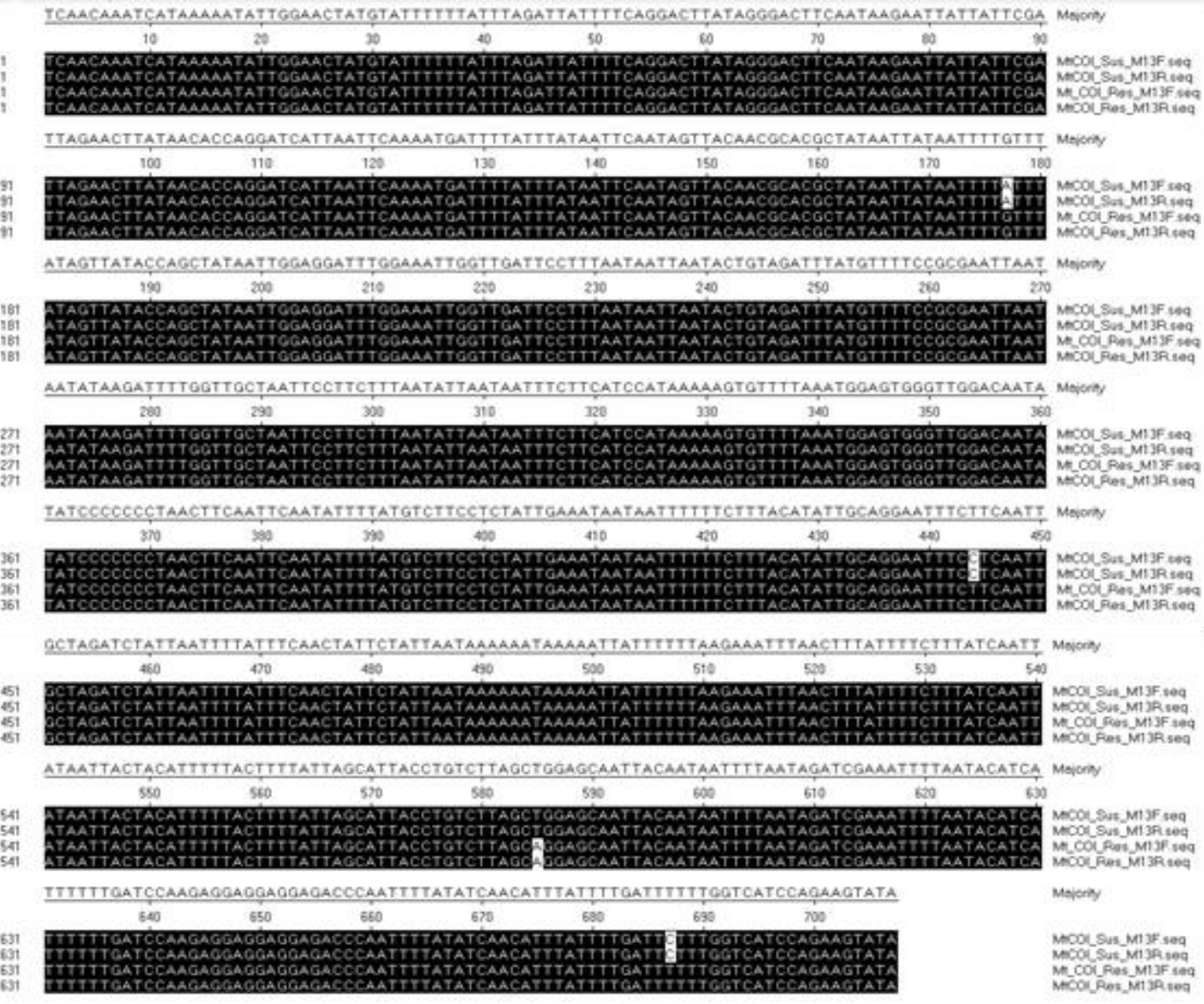


Fig.6 Derived amino acid sequences of COI region variants of T. urticae

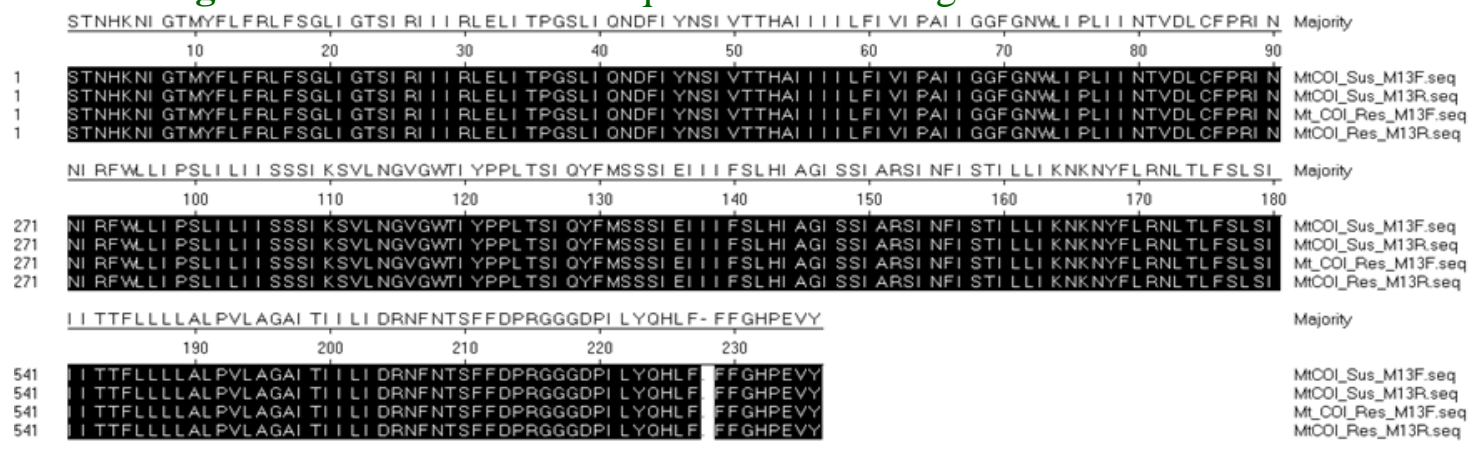

So the consensus sequence of their alignment was blasted in NCBI database and this showed high level of similarity with the existing COI sequences. The low to moderate level of resistance in the selected population has not shown any change in the amino acid sequences and thus no change in the protein structure. Navajas et al., (1998) and Xie et al., (2006b) while characterizing ten different strains based on COI region, detected a total of six haplotypes which showed no insertions or deletions in the sequenced region. The COI region has been almost widely accepted for barcoding animals because of its generally conserved priming sites. Moreover the evolution of this gene is rapid enough to allow the discrimination of not only closely allied species, but also phylogeographic groups within a single species (Cox and Herbert, 2001, Wares and Cunningham, 2001). When looking at the genetic distance between strains expressed as nucleotide divergence of COI sequence, there was no correlation between COI polymorphism, geographical location of sampling and resistance status. Thus most of the studies have reported COI as a stable gene which is least influenced by insecticide/ acaricide resistance. In our studies high level of resistance to fenazaquin didn't show any change in the amino acid sequence of COI region of resistant and susceptible populations.

\section{Acknowledgement}

Authors are thankful to the Indian Council of Agricultural research, New Delhi (All India
Network Project on Agricultural Acarology), for the financial assistance and to the Punjab Agricultural University, Ludhiana for providing the necessary research facilities.

\section{References}

Anonymous. 2013. Progress Report 2011-13. All India Network Project on Agricultural Acarology, UAS, GKVK, Bangalore.

Behura, S. K. 2006. Molecular marker systems in insects: current trends and future avenues. Molecular Ecology. 15: 3087 3113

Belay, T., Goftishu, M and Kassaye, A. 2018. Management of an emerging pest, Tetranychus urticae Koch (Acari: Tetranychidae), with pesticides in Eastern Ethiopia. African Crop Science Journal. 26: $291-304$

Catania, F., Kauer, M. O., Daborn, P. J., Yen, J. L., Ffrench-Constant, R. $\mathrm{H}$ and Schlotterer, C.2004. World-wide survey of an Accord insertion and its association with DDT resistance in Drosophila melanogaster. Mol Ecol. 13:2491-2504.

Cho, J. R., Kim, Y. J., Ahn, Y. J., Yoo, J. K and Lee, J. O. 1995. Monitoring of acaricide resistance in field collected populations of Tetranychus urticae (Acari: Tetranychidae) in Korea. Korean J Appl Entomol. 31: 40-45.

Citation: Cazaux, M., Navarro, M., Bruinsma, K.A., Zhurov, V., Negrave, T., Van Leeuwen, T., Grbic, V., Grbic, M. Application of Two-spotted Spider 
Citation: Cazaux, M., Navarro, M., Bruinsma, K.A., Zhurov, V., Negrave, T., Van Leeuwen, T., Grbic, V., Grbic, M. Application of Two-spotted Spider

Citation: Cazaux, M., Navarro, M., Bruinsma, K.A., Zhurov, V., Negrave, T., Van Leeuwen, T., Grbic, V., Grbic, M. Application of Two-spotted Spider

Cox, A. J and Hebert, P. D. N. 2001. Colonization, extinction and phylogeographic patterning in a freshwater crustacean. Mol. Ecol. 10: 371-386.

Croft, B. A and Van, H. E. 1988. Ecological and genetic factors influencing evolution of pesticide resistance in tetranychid and phytoseeid mites. Exp Appl Acarol. 4: 277-300.

Dhar, T., Dey, P. K and Sarkar, P. K. 2000. Influence of abiotic factors on population build-up of red spider mite, Tetranychus urticae on okra vis a vis evaluation of some new pesticides for their control. Pestology. 24: 34-37.

Feyereisen, R. 2005. Insect cytochrome P450, In: Gilbert L I, Latrou K and Gill S S (Eds.) Comprehensive Insect Physiology, Biochemistry, Pharmacology and Molecular Biology, Elsevier, Amsterdam. Pp. 1-77.

Herron, G. A and Rophail, J. 1998. Tebufenpyrad (Pyranica) resistance detected in two-spotted spider mite Tetranychus urticae Koch (Acari: Tetranychidae) from apples in Western Australia. Exp Appl Acarol. 22: 633-41.

Hinomoto, $\mathrm{N}$ and Takafuji, A. 2001. Genetic diversity and phylogeny of the Kanzawa spider mite, Tetranychus kanzawai, in Japan. Exp Appl Acarol. 25: 355-70.

Hinomoto, N., Osakabe, M., Gotoh, T and Takafuji, A. 2001. Phylogenetic analysis of green and red forms of the two-spotted spider mite, Tetranychus urticae Koch (Acari: Tetranychidae), in Japan, based on mitochondrial cytochrome oxidase subunit I sequences. Appl Entomol Zool. 36: 459-64.

Hinomoto, N., Tran, D. P., Pham, A. T., Le,
T.B.N., Tajima, R., Ohashi, K., Osakabe, $\mathrm{M}$ and Takafuji, A. 2007. Identification of spider mites (Acari: Tetranychidae) by DNA sequences: a case study in Northern Vietnam. Int J Acarol. 33: 53-60.

Hollingworth, R. M and Ahammadsahib, K. I. 1995. Inhibitors of respiratory complex 1 : mechanisms, pesticidal actions and toxicology. Rev Pestic Toxicol. 3: $277-$ 302.

Jeppson, L. R., Keifer, H. H and Baker, E. W. 1975. Mites injurious to economic plants, Univ. Calf. Press. 614.

Knowles, C. O. 1997. Mechanisms of resistance to acaricides. In: Sjut V (ed) Molecular mechanisms of resistance to agrochemicals, Berlin: Springer Verlag. 13: $57-77$.

Maitra, S., Dombrowski, S. M., Basu, M., Raustol, O., Waters, L. C and Ganguly, R. 2000. Factors on the third chromosome affect the level of CYP6A2 and CYP6A8 expression in Drosophila melanogaster. Gene. 248: 147-56.

Mite Tetranychus urticae for Plant-pest Interaction Studies. J. Vis. Exp. (89), e51738, doi:10.3791/51738 (2014)

Mite Tetranychus urticae for Plant-pest Interaction Studies. J. Vis. Exp. (89), e51738, doi: 10.3791/51738 (2014)

Mite Tetranychus urticae for Plant-pest Interaction Studies. J. Vis. Exp. (89), e51738, doi:10.3791/51738 (2014)

Navajas, M., Cotton, D., Kreiter, S and Gutierrez, J.1992. Molecular approach in spider mites (Acari: Tetranychidae): preliminary data on ribosomal DNA sequences. Exp Appl Acarol. 15: 211-18.

Navajas, M., Fournier, D., Lagnel, J., Gutierrez, $\mathrm{J}$ and Boursot, P. 1996a. Mitochondrial COI sequences in mites: evidence for variations in base composition. Insect $\mathrm{Mol}$ Biol. 5: 281-85.

Navajas, M., Gutierrez, J., Bonato, O., Bolland, H. R and Mapangoudivassa, S.1994. Intraspecific diversity of the cassava green mite Mononycellus progresivus (Acari, Tetranychidae) using comparisons of mitochondrial and nuclear ribosomal 
DNA-sequences and cross-breeding. Exp Appl Acarol. 18: 351-60.

Navajas, M., Gutierrez, J., Lagnel, J and Boursot, P. 1996b. Mitochondrial cytochrome oxidase I in tetranychid mites: a comparison between molecular phylogeny and changes of morphological and life history traits. Bull Entomol Res. 86: 407-17

Navajas, M., Lagnel, J., Gutierrez, J and Boursot, P. 1998. Species-wide homogeneity of nuclear ribosomal ITS2 sequences in the spider mite Tetranychus urticae contrasts with extensive mitochondrial COI polymorphism. Heredity. 80: 742-52.

Ramasubramanian, R., Ramaraju, $\mathrm{K}$ and Regupathy, A.2005. Acaricide resistance in Tetranychus urticae Koch (Acari: Tetranychidae)-Global Scenario. $J$ Entomol. 2: 33-39.

Sharma, R. K and Bhullar, M. B. 2018. Status of acaricide resistance in field collected two-spotted spider mite, Tetranychus urticae Koch from vegetable growing areas of Punjab, India. Journal of Entomology and Zoology Studies. 6:328332

Sharma, R. K., Bhullar, M. B., Singh, S and Jindal, V. 2018. Molecular analysis of fenazaquin selected resistant strain of two-spotted spider mite, Tetranychus urticae Koch. Indian Journal of Biotechnology. 17: 602-610.

Stumpf, N and Nauen, R. 2001. Crossresistance, inheritance, and biochemistry of mitochondrial electron transport inhibitor-acaricide resistance in Tetranychus urticae (acari: tetranychidae). Econ Entomol. 94: 1577-
83.

Toda, S., Osakabe, M and Komazaki, S. 2000. Interspecific diversity of mitochondrial COI sequences in Japanese Panonychus species (Acari: Tetranychidae). Exp Appl Acarol. 24: 821-29.

Van Leeuwan, T. V., Dermauw, W., Tirry, L., Vontas, J and Tsagkarakou, A. 2010. Acaricide resistance mechanisms in the two spotted spider mite Tetranychus urticae and other important Acri. Insect Biochem Mol Biol. 40: 563-71.

Van Pottelberge, S., Van Leeuwen, T., Nauen, $\mathrm{R}$ and Tirry, L. 2009. Resistance mechanisms to mitochondrial electron transport inhibitors in a field-collected strain of Tetranychus urticae Koch (Acari: Tetranychidae). Bull Entomol Res. 99:23-31.

Vogler, A. P and Monaghan, M. T. 2007. Recent advances in DNA taxonomy. $J$ Zool Syst Evol Res. 45: 1-10.

Wares, J. P and Cunningham, C. W. 2001. Phylogeography and historical ecology of the North Atlantic intertidal. Evolution. 12: 2455-2469.

Xie, L., Hong, X. Y and Xue, X. F. 2006a. Population genetic structure of the twospotted spider mite (Acari: Tetranychidae) from China. Ann Entomol Soc Am. 99: 959-65.

Xie, L., Miao, H and Hong, X.Y. 2006b. The two-spotted spider mite Tetranychus urticae Koch and the carmine spider mite Tetranychus cinnabarinus (Boisduval) in China mixed in their Wolbachia phylogenetic tree. Zootaxa. 1165: 33-46.

Zhang, Z. 2003. Mites of Greenhouses, CABI Publishing Oxon, UK. 244.

\section{How to cite this article:}

Rakesh Kumar Sharma, Manmeet Brar Bhullar and Satnam Singh. 2019. Mitochondria COI-Based Molecular Characterization and Genetic Analysis of the Fenazaquin Selected Resistant Strain of Two-Spotted Spider Mite, Tetranychus urticae Koch. Int.J.Curr.Microbiol.App.Sci. 8(02): 25082517. doi: https://doi.org/10.20546/ijcmas.2019.802.292 